\title{
Active QQQ Covered Call Strategies
}

\author{
David P. Simon \\ Finance Department \\ Bentley University \\ Waltham, MA 02452 \\ Dsimon@bentley.edu.
}

Tele: (781) 8912489

October 21, 2013

\begin{abstract}
This study examines QQQ covered call strategies from January 2002 through January 2012 and finds that downside risk-adjusted returns are attractive both on an absolute basis and relative to those of long QQQ positions. The study then presents a framework that partitions covered call positions into delta-neutral short call and long equity positions, which highlights the separability of decisions about delta-neutral short option and long equity exposure within a broader class of short call strategies that includes covered calls. The study then demonstrates that selling QQQ call options and buying QQQ shares on a delta-neutral basis, both without and with delta rebalancing, offers attractive risk-reward tradeoffs. The study then constructs out-ofsample implied volatility fitted values and examines the performance of covered call and deltaneutral short call strategies when estimates indicate that implied volatility is more overpriced than usual. These conditions substantially enhance the performance of covered call strategies as well as short delta-neutral call strategies.
\end{abstract}


Recent studies that have examined the profitability of covered call strategies have focused primarily on S\&P 500 index options. ${ }^{1}$ Whaley [2002] examines the CBOE Buy-Write Index (BXM), which involves buying the S\&P 500 Index and selling one-month, at-the-money covered calls on monthly option expiration dates. He demonstrates that from June 1988 through December 2001, the BXM earned $1.12 \%$ mean monthly returns, versus $1.19 \%$ for the S\&P 500, but with a substantially lower standard deviation of $2.66 \%$, versus $4.10 \%$ for the S\&P $500 .^{2}$ These results highlight the attractive risk-adjusted returns of passive covered call strategies and have contributed to their popularity.

Hill et al. [2006] examine the sources of profitability of the BXM strategy and emphasize the tradeoffs between the benefits of receiving option premiums from selling calls versus the potential costs of having to sell the S\&P 500 at the strike prices of the calls sold when the S\&P 500 is considerably higher at expiration. Hill et al. [2006] demonstrate that the profitability of these strategies owes mainly to the tendency of at-the-money S\&P 500 index options to be priced at implied volatilities that exceeded subsequent actual volatilities by an average 2.4 percentage points from 1990 through 2005. The variation of the extent to which implied volatilities are greater than future one-month actual volatilities suggests that discretionary strategies of selling covered calls only when implied volatility is estimated to be more overpriced than usual could enhance risk-adjusted returns. Hill et al. [2006] do not explore this possibility but instead examine strategies of selling further-out-of-the-money calls when implied volatility is higher and

\footnotetext{
${ }^{1}$ A notable exception is Szado and Kapadia [2007], who examine the profitability of Russell 2000 Index covered call strategies.

${ }^{2}$ The CBOE introduced the BXM in 2002, and thus Whaley's [2002] study is based on BXM index levels constructed for the index before it was launched. The Chicago Board Options Exchange also introduced the Nasdaq 100 Buy-Write index (BXN) in 2005, which is based on Nasdaq 100 Index options rather than the much more liquid and heavily traded QQQ options examined in this study.
} 
closer-to-the-money calls when implied volatility is lower. These authors find, however, that the performances of these active strategies are only about in line with fixed-strike strategies that have similar initial average deltas. ${ }^{3}$

Figelman [2008] more formally decomposes the returns of covered call strategies into a volatility premium — the difference between implied volatility and subsequent actual volatility over the life of options, the equity risk premium, and interest rate levels. The volatility premium reflects the benefit from the tendency of implied volatility to be higher than subsequent realized volatility, and the second factor reflects a reduction in the equity risk premium earned because potential returns are truncated when call options are sold against long positions. ${ }^{4}$ From this perspective, a greater expected equity market risk premium makes covered call strategies less attractive unless offset by a greater expected volatility premium.

The present study examines Nasdaq 100 Exchange-Traded Fund (QQQ) covered call strategies, which unlike S\&P 500 covered call strategies have received little attention. ${ }^{5}$ We first examine the downside risk-adjusted returns of passive strategies that involve buying QQQ shares and selling an equivalent amount of one-month calls with various moneyness. We then present a

\footnotetext{
${ }^{3}$ Hill et al. [2006] specifically use implied volatilities to infer the probabilities of options ending in the money and examine the returns of covered call strategies with options that have $20 \%$ and $30 \%$ chances of ending in the money. Delta is the derivative of option prices with respect to a change in the price of the underlying instrument.

${ }^{4}$ The interest rate factor stems from the fact that the leverage embedded in call options is worth more and call option prices are higher when the cost of funds is greater.

${ }^{5}$ To the author's knowledge, no study has focused on QQQ covered call strategies, although Szado and Kazemi [2009] and Szado and Schneeweis [2011] examine QQQ collar strategies that involve protecting QQQ portfolios by buying puts and selling out-of-the-money calls to defray part of the cost of protection. Renicker and Mallick [2005] briefly examine the returns on QQQ covered call strategies but primarily focus on S\&P 500 Index covered call strategies. Simon [2007] examines the profitability of selling QQQ straddles and strangles. Other studies that examine S\&P 500 covered call strategies include Schneeweis and Spurgin [2001], Feldman and Roy [2005] and Callan Associates [2006].
} 
framework along similar lines as Figelman [2008], whereby covered call strategies are partitioned into decisions about short delta-neutral call option exposure and equity exposure. This broader framework highlights the possibility that promising alternatives to passive covered call strategies could involve (1) varying the quantity of call options sold on a delta-neutral basis in response to estimates of the ex ante volatility premium and (2) separately adjusting the amount of long equity exposure based on assessments of the equity risk premium. We then focus on the former component of covered call returns and examine the returns from selling one-month QQQ call options on a delta-neutral basis, first without and then with delta rebalancing. We then assess the results of implementing these strategies only when estimates suggest that the volatility premium is higher than usual. To this end, we estimate a model of the QQQ Volatility Index (QQV), which measures the implied volatility of one-month, at-the-money QQQ options, and then construct out-of-sample fitted values of the QQQ volatility index. We then assess the profitability of QQQ covered call strategies and delta-neutral short call positions when the QQQ volatility index is unusually high relative to out-of-sample fitted values.

The results demonstrate that the downside risk-adjusted returns of passive QQQ covered call and delta-neutral short call strategies are attractive from January 2002 through January 2012. The findings also demonstrate considerably more favorable downside risk-adjusted returns on both covered call and delta-neutral short call strategies when out-of-sample estimates indicate that the volatility premium is unusually high. Finally, rebalancing deltas substantially lowers downside volatility on originally delta-neutral short call strategies with little sacrifice to return and hence further enhances downside risk-adjusted returns.

The next section provides background information on QQQ options and a preliminary data analysis and then reports on the profitability of passive covered call strategies. The third 
section presents a framework for analyzing covered call strategies and then examines the returns on delta-neutral short call positions. The fourth section estimates a parsimonious model of QQQ option-implied volatility to construct out-of-sample estimates of the QQQ volatility premium and then examines the profitability of covered call strategies and delta-neutral short call strategies when the QQQ volatility premium is estimated to be in its highest quartile. The final section summarizes the results and discusses the implications of the findings.

\section{THE PERFORMANCE OF PASSIVE QQQ COVERED CALL STRATEGIES}

This section examines the risk-adjusted returns of QQQ covered call strategies from January 2002 through January 2012. Although QQQ option trading began in March 1999, we do not include periods before 2002 because doing so would capture more of the technology stock bust than the boom and would substantially bias upward the performance of QQQ covered call strategies relative to long QQQ positions. By beginning the sample period in January 2002, we sidestep both the roughly doubling of QQQ share prices from spring 1999 through the peak one year later and, more importantly, the loss of roughly two-thirds of the value of QQQ shares from the peak to the beginning of $2002 .^{6}$

In this section, we examine passive one-month covered call strategies for QQQ options that are at the money (ATM), 2\% and 4\% out of the money (OTM), and 2\% in the money

\footnotetext{
${ }^{6}$ QQQ share prices closed at 102.12 on March 10, 1999; rose to a peak of 230 at the close on March 9, 2000; and closed at 40.11 on January 2, 2002, after a 2 for 1 split on March 20, 2000.
} 
(ITM). ${ }^{7}$ We assume that on monthly option expiration days, one-month QQQ call options are sold at the closing bid quote and QQQ shares are bought at the last transaction price of the day. The calculations assume that short option positions are held through expiration and are worth their intrinsic value at expiration. Dividends are included in returns, and the outlay used to calculate returns on covered call strategies equals the cost of 100 QQQ shares purchased each month, net of the premium received for selling one call option contract. ${ }^{8}$ The data used in this study are from OptionMetrics. The returns on covered call positions are

$$
R_{c c}=\frac{S_{t}+D_{t}-C_{t}}{S_{t-1}-C_{t-1}}-1,
$$

where the numerator is the value of 100 QQQ shares plus any dividends received minus the intrinsic value at expiration of the call that was sold, and the denominator represents the cost of buying 100 QQQ shares net of the proceeds from selling one call at the close of the previous expiration.

Because covered call strategies involve limited potential returns and unlimited potential losses (up to the price of the underlying instrument falling to zero), covered call return distributions often are non-normal, and hence return standard deviations and Sharpe ratios can be

\footnotetext{
${ }^{7}$ We focus on one-month QQQ options to economize on space and also because anecdotal evidence suggests that covered call strategies most often involve selling one-month calls, as time decay generally is greatest for short-term options.

${ }^{8}$ For the sake of comparison with other studies that examine covered call strategies, such as Whaley [2002], Hill et al. [2006], and Szado and Kapadia [2007], we assume that the only transaction cost incurred owes to bid-ask spreads on calls that are sold, and thus we abstract from bid-ask spreads on shares and brokerage fees. These assumptions have relatively minor effects on the results because bid-ask spreads on QQQ shares typically are no more than one cent and because discount brokers offer all-inclusive brokerage fees of only 50 cents per option contract and \$1 for 100-share stock transactions.
} 
highly misleading measures of risk and risk-adjusted returns, respectively. As a result, we focus on downside risk and report semi-standard deviations and Sortino ratios, although we also report standard deviations and Sharpe ratios for completeness. ${ }^{9}$

Exhibit 1 provides background information on the data used in this study. The mean midpoint QQQ option prices range from 1.63 for $2 \%$ ITM calls to 0.46 for $4 \%$ OTM calls. ${ }^{10}$ These option prices average $4.0 \%$ to $1.1 \%$ of QQQ prices. Bid-ask spreads average about 4 cents but have fallen sharply in recent years. ${ }^{11}$ Implied volatilities are higher at lower strike prices, and thus QQQ implied volatilities have the same volatility skew pattern as S\&P 500 index options. ${ }^{12}$ Average implied volatility ranges from $26.08 \%$ for $2 \%$ ITM calls to $23.20 \%$ for $4 \%$ OTM calls. In addition, the average implied volatilities of QQQ options exceed the average subsequent actual volatility of $22.65 \%$ during the sample period. The average volatility premium of ATM calls is 2.38 percentage points, which is very close to the 2.4 percentage point volatility premium Hill et al. [2006] report for one-month ATM S\&P 500 index options. Deltas range from 0.64 for $2 \%$ ITM calls to 0.27 for $4 \%$ OTM calls. Finally, the QQV, which reflects the implied volatility of one-month QQQ options and is used later to assess the QQQ volatility premium, averages

\footnotetext{
${ }^{9}$ For semi-standard deviation calculations, gains are set equal to zero and included in the calculations. Sortino Ratios are calculated with the minimum acceptable profit equal to zero and thus are equal to the mean return scaled by the semi-standard deviation.

${ }^{10}$ We assume that call options with moneyness closest to each moneyness category are sold each month. Because strike prices are one point apart over the vast majority of the sample period and because QQQ share prices traded to as low as roughly 20 over the sample period, the same call option sometimes is used for different moneyness categories. For example, the strike that is closest to being 2\% OTM may also be the closest to being ATM and in these cases would be used to calculate both returns. The exception to strike prices being one point apart during the sample period occurred when the strike prices of existing QQQ options were adjusted owing to a special \$3.08 dividend paid by Microsoft in November 2004.

${ }^{11}$ The mean bid-ask spread of the options in Exhibit 1 range from 1.1 to 1.4 cents from January 2010 through January 2012.

${ }^{12}$ OptionMetrics calculates implied volatilities and the greeks using a binomial framework that accommodates the early exercise feature of American options such as QQQ options and incorporates dividends.
} 
$24.63 \%$ on expiration dates, which is fairly close to the $25.03 \%$ average implied volatility of ATM calls.

Exhibit 2 shows the results of one month QQQ covered call strategies from January 2002 through January 2012. The mean monthly returns of covered call strategies either match or exceed the $0.61 \%$ mean monthly QQQ returns. Mean monthly returns of covered call strategies range from $0.61 \%$ for $2 \%$ ITM strategies to $0.77 \%$ for $4 \%$ OTM strategies. More importantly, the returns on covered call strategies have substantially lower downside risk than long QQQ positions, and not surprisingly, the downside risk of covered call strategies is reduced by selling lower strike calls. The latter owes to the greater buffer against losses and the lower breakeven points associated with selling higher-priced, lower strike calls. Semi-standard deviations of covered call returns range from $3.24 \%$ for $2 \%$ ITM strategies to $4.26 \%$ for $4 \%$ OTM strategies, compared with $4.85 \%$ for QQQ returns. Overall, the downside risk-adjusted returns of covered call strategies are higher than those of long QQQ positions, as reflected by Sortino ratios, which range from 0.175 for $2 \%$ OTM covered calls to 0.190 for ATM covered calls, versus 0.126 for long QQQ positions. Similar conclusions are reached when standard deviations and Sharpe ratios are used as measures of risk and risk-adjusted returns, respectively. ${ }^{13}$

The average size of gains relative to losses is lower for covered calls compared with long QQQ positions, owing to the limited potential returns and unlimited potential losses of covered calls. The smaller average gain of covered calls relative to long QQQ positions is more than offset by more-favorable frequencies of gains. For covered call strategies, the frequency of gains ranges from as high as $79 \%$ for $2 \%$ ITM covered calls to $68 \%$ for $4 \%$ OTM covered calls,

\footnotetext{
${ }^{13}$ The standard deviation of QQQ returns is 6.65\%, which compares with standard deviations ranging from 3.86\% for $2 \%$ ITM covered calls to $5.55 \%$ for $4 \%$ OTM covered calls. Sharpe ratios for covered call positions range from 0.141 to 0.158 , versus 0.092 for long QQQ positions.
} 
whereas for outright long QQQ positions, the percentage of gains is 59\%. From a risk management perspective, the results also demonstrate that covered call strategies substantially reduce the magnitude of large losses, as the bottom decile cutoff of returns for covered call strategies ranges from $-3.08 \%$ to $-6.09 \%$, compared with $-7.08 \%$ for long QQQ positions.

Exhibit 3 shows the cumulative gains including dividends from investing \$1,000 in QQQ covered call strategies versus QQQ shares from January 2002 through January 2012. The exhibit shows that $\$ 1,000$ invested in covered call strategies grew to roughly $\$ 2,000$ during the sample period, with little difference across moneyness categories. By contrast, the same amount invested in QQQ shares grew to only \$1,600 during the sample period. Exhibit 3 also shows that the cumulative gains from covered call strategies fell sharply in sympathy with QQQ prices during the financial panic beginning in 2008 but did not turn negative during this period, largely owing to substantial gains in earlier years. By contrast, the cumulative value of QQQ shares from the beginning of 2002 was down about $30 \%$ during the financial panic. Overall, the results indicate that one-month QQQ covered call strategies offer attractive downside risk-adjusted returns relative to long QQQ strategies. The next section of this study provides a framework for examining covered call strategies and then examines the returns on delta-neutral short call positions.

\section{A FRAMEWORK FOR ASSESSING COVERED CALL STRATEGIES}

As demonstrated by Hill et al. [2006], Szado and Kapadia [2007], and Figelman [2008], covered call strategies involve tradeoffs between a) earning volatility premiums stemming from the tendency of implied volatility to be higher than subsequent actual volatility and b) earning 
less of the equity premium. The former results from selling options that historically were overpriced, whereas the latter results from having to sell the underlying stock at the strike price of call options sold when stock prices are substantially higher at expiration.

Covered call positions can be partitioned into long equity and delta-neutral short call positions, which can be seen most easily with an example. Suppose that an investor buys 100 QQQ shares and sells a 2\% OTM call that has a delta of 0.40 . If the 100 shares are partitioned into 40 and 60 shares, the long 40 shares combined with the short 40 delta call is a delta-neutral short call position, leaving the investor also long 60 shares. This framework underscores the fact that the delta of the call sold determines the relative magnitudes of the delta-neutral short option position and the long share position. When investors sell a further-out-of-the money covered call, the delta of the call is lower and more of the overall position is an outright long stock position.

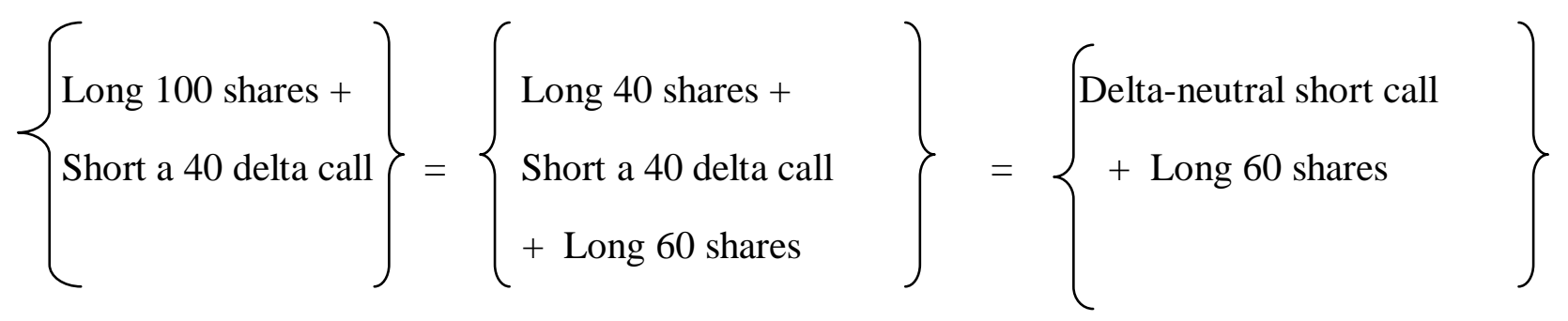

After selling a covered call, delta moves unfavorably as the stock price changes because of the negative gamma of a short call position. ${ }^{14}$ If the stock price increases, the delta rises and the delta-neutral short call position remains delta neutral only if in the above framework the

\footnotetext{
${ }^{14}$ The sensitivity of delta to a change in the underlying stock price is referred to as gamma, which is typically scaled to reflect the change of delta for a one-point change in the price of the underlying instrument. Covered call and short call positions more generally have negative gamma because as the price of the underlying instrument rises (falls), the delta of the call sold rises (falls) and hence is more (less) responsive to further increases (decreases) in the price of the underlying instrument, both of which are detrimental to the call option seller.
} 
number of shares allocated to the delta-neutral short option position rises and the size of the long stock position decreases. Ultimately, as the stock price rises further, the delta of the call goes to one and the size of the outright long share position goes to zero, because all of the shares are required to make the call that was sold delta neutral. At this point, the covered call position has a delta of zero. By contrast, if the stock price falls, the delta of the call that was sold falls and fewer shares are required to make the short call position delta neutral, which increases the size of the outright long share position. If the stock price continues to fall, the delta of the call ultimately goes to zero and the covered call position has the characteristics of a long equity position.

In this general framework in which covered call positions are viewed as initially deltaneutral short call and long equity positions, decisions about the amount of short call option exposure and long equity exposure are separable. The choice of the former should depend primarily on views about the extent to which options are overpriced in the context of the current market environment, or equivalently, implied volatility is high relative to forecasts of subsequent actual volatility. Before we examine strategies conditioned on high estimated levels of the volatility premium, we first examine the outcomes of selling one-month call options on option expiration dates on an originally delta-neutral basis, both without and with delta rebalancing. The returns on these strategies are calculated as

$$
R_{\Delta \text { Neutral }}=\frac{\Delta\left[S_{t}+D_{t}\right]-C_{t}}{\Delta S_{t-1}-C_{t-1}}-1
$$

where delta QQQ shares are purchased against the sale of one QQQ call option for which $\Delta$ is the delta of the call option. The numerator is equal to the ending value of the delta shares of 
QQQ plus any dividends earned on these shares minus the intrinsic value of the call at expiration, and the denominator is the amount paid for the delta shares of QQQ net of the proceeds received from selling a call option.

Exhibit 4 shows the results of selling delta-neutral one-month QQQ call options that are 2\% ITM, ATM, 2\% OTM, and 4\% OTM without delta rebalancing. The average deltas of these options when they are sold are $0.64,0.53,0.40$, and 0.27 , respectively. Thus, on average 64,53 , 40, and 27 shares are purchased for these respective options. The results indicate that average monthly returns of delta-neutral short call positions range from a low of $0.69 \%$ for $2 \%$ ITM calls to a high of $1.12 \%$ for $4 \%$ OTM calls. The finding that returns increase monotonically from low to high strike options is counter to what might be expected based on the volatility skew, which suggests that lower strike options are more overpriced than higher strike options. ${ }^{15}$ Given the (unreported) average initial vega of 4.3 of $2 \%$ ITM calls, however, the roughly 3 percentage point higher implied volatility of these options versus the 4\% OTM calls shown in Exhibit 1 causes the average $\$ 1.63$ selling price of the $2 \%$ ITM calls to be only 13 cents higher than if they were priced at the average implied volatility of the 4\% OTM calls.

The results also indicate that the mean returns of delta-neutral short call positions without delta rebalancing exceed those of long QQQ positions and with substantially lower risk. Semistandard deviations rise monotonically with higher strike prices, from a low of $2.65 \%$ for $2 \%$ ITM calls to $3.73 \%$ for $4 \%$ OTM calls, compared with $4.85 \%$ for long QQQ positions. The

\footnotetext{
${ }^{15}$ See Ederington and Guan [2002] for evidence that delta- and vega-neutral S\&P 500 index option portfolios that are long options with low implied volatilities and short options with high implied volatilities are profitable—but only before transactions costs.
} 
higher mean returns and lower downside risk translate into Sortino ratios that are well above those of long QQQ positions and vary from 0.24 to 0.30 , versus 0.13 for long QQQ positions. ${ }^{16}$

These results assume that delta-neutral call sellers do not reduce risk by rebalancing deltas after they enter positions. Nevertheless, the lowest-decile return cutoffs range from $2.67 \%$ to $-5.97 \%$, compared with $-7.08 \%$ for long QQQ positions. The absence of delta rebalancing leads to substantial losses when QQQ prices either rise or fall sharply because of the negative gamma of delta-neutral short call positions. Unreported results indicate that when QQQ returns are in their highest decile and average $10.05 \%$, the mean return of ATM short QQQ call strategies is $-1.78 \%$. Likewise, when QQQ returns are in their lowest decile and average $12.64 \%$, the mean return of ATM short QQQ call strategies is $-6.43 \%$. Thus, extreme QQQ price changes lead to large losses on originally delta-neutral short call positions as deltas turn substantially negative in the event of large QQQ price rallies or turn substantially positive in the event of large QQQ price declines. ${ }^{17}$

We next examine the returns of delta-neutral short call positions assuming that deltas are rebalanced to zero by buying QQQ shares when overall deltas fall below -25 and by selling QQQ shares when overall deltas rise above $25 .{ }^{18}$ Because deltas become increasingly positive as QQQ share prices fall and increasingly negative as QQQ prices rise, delta rebalancing involves

\footnotetext{
${ }^{16}$ Similarly, Sharpe ratios vary from 0.17 to 0.21 for delta-neutral short call positions, versus 0.09 for long QQQ positions.

${ }^{17}$ The considerably larger losses associated with extreme negative QQQ returns compared with extreme positive QQQ returns result from the tendency of extreme negative returns to occur at higher QQQ levels than extreme positive returns during the sample period and thus to be associated with substantially greater average absolute QQQ price changes ( -5.2 versus 3.5$)$.

${ }^{18}$ We use the term delta rebalancing rather than delta hedging to imply that deltas are adjusted only after they breach fairly wide bands, whereas delta hedging typically connotes adjusting deltas more actively.
} 
buying QQQ shares after QQQ prices have risen and selling QQQ shares after QQQ prices have fallen. ${ }^{19}$ We assume that the same amount of funds are initially allocated to the positions as in the previous simulations, and we calculate profits as in Equation (2), augmented by the gains or losses on QQQ shares bought or sold to rebalance deltas. We abstract from the impact of delta hedging on both the investment proceeds from funds freed up when QQQ shares that were originally purchased are sold, as well as the cost of borrowing the funds required when additional shares are purchased, which is tantamount to assuming that investors have funds in money market accounts that are augmented or tapped when needed. This assumption has little effect on the results because of the short horizons examined, the very low interest rates during much of the sample period, and because rebalancing deltas requires, on balance, roughly as much additional funds as it frees up during the sample period.

The results in Exhibit 5 indicate that delta rebalancing substantially improves riskadjusted returns. Mean monthly returns with rebalancing range from $0.59 \%$ to $1.19 \%$, compared with $0.69 \%$ to $1.12 \%$ without rebalancing, while semi-standard deviations range from $1.05 \%$ to $2.54 \%$ with rebalancing, versus $2.65 \%$ to $3.73 \%$ without rebalancing. The lower downside risk results in Sortino ratios from 0.45 to 0.59 , which are about double those without rebalancing. The Sortino ratios are also three to four times greater than those of long QQQ positions. ${ }^{20}$ Unreported results indicate that delta rebalancing occurs on average twice per option per expiration cycle, with little variation across moneyness categories. In addition to reducing semi-

\footnotetext{
${ }^{19}$ Delta rebalancing should improve risk-adjusted returns when QQQ prices trend either higher or lower, and it should hurt risk-adjusted returns when QQQ prices move within a trading range. The latter results from rebalancing by buying shares at the high end of a trading range and selling shares at the low end of the trading range.

${ }^{20}$ The standard deviations are similarly lower and Sharpe ratios are higher with delta rebalancing. Sharpe ratios with delta rebalancing range from 0.27 to 0.34 , compared with 0.17 to 0.21 without delta rebalancing.
} 
standard deviations, delta rebalancing also substantially lowers the average size of losses and raises the cutoff for the bottom decile of returns for each moneyness category. For example, the average size of losses and the cutoff for the bottom decile of returns for $2 \%$ OTM calls are $1.77 \%$ and $-1.90 \%$ with rebalancing, versus $-3.92 \%$ and $-4.69 \%$ without rebalancing. The results are similar for other moneyness categories. Overall, the results indicate that the deltaneutral short call component of covered call strategies offers compelling risk-adjusted returns, which are enhanced substantially by rebalancing deltas. ${ }^{21}$

\section{ACTIVE STRATEGIES BASED ON ESTIMATES OF THE VOLATILITY PREMIUM}

\section{Background and Methodology for Estimating the Volatility Premium}

This study has demonstrated that QQQ covered call strategies and delta-neutral short QQQ call strategies provide attractive risk-adjusted returns during the sample period. We next examine whether risk-adjusted returns are enhanced when out-of-sample estimates indicate that the volatility premium is unusually high. Previous studies such as Hill et al. [2006], Szado and Kapadia [2007], and Figelman [2008] demonstrate that the volatility premium - the tendency of implied volatility to be greater than subsequent actual volatility-is a key component of covered call returns. For example, Szado and Kapadia [2007] re-examine Russell 2000 Index covered call returns assuming that the options sold are priced at the realized volatility for the remainder of their lives. The authors demonstrate that covered call strategies underperform the index during their sample period from 1996 through 2006.

\footnotetext{
${ }^{21}$ Unreported results demonstrate that more-active delta rebalancing further reduces downside risk with little sacrifice of return. For example, rebalancing when deltas are above 10 or below -10 for $2 \%$ OTM short call strategies results in $0.74 \%$ monthly mean returns and semi-standard deviations of $1.01 \%$. This translates into a Sortino ratio increase to 0.73 with more-active rebalancing, versus the .57 Sortino ratio that was reported.
} 
We next examine whether the performances of covered call and delta-neutral short call positions are enhanced when entered only when implied volatility is unusually high relative to out-of-sample implied volatility estimates. We use the QQV as a measure of implied volatility rather than the implied volatilities of specific options because the former is a more robust measure of implied volatility. The American Stock Exchange began reporting the QQV on a real-time basis in January 2001 and constructed the index back to March 1999. The QQV is formed using the same methodology as the original VIX and is interpolated to reflect the implied volatility of one-month, at-the-money options from the implied volatilities of the two calls and the two puts that are closest to the money of the two front contract months that have more than eight days until expiration. We estimate a parsimonious model of the QQV and construct out-ofsample fitted QQV values. The difference between the actual QQV and these fitted values is then used as a gauge of the expensiveness of QQQ options in light of the market environment and subsequently is referred to as the conditional volatility premium. ${ }^{22}$ We then examine the results of entering covered call positions and delta-neutral short call positions when the conditional volatility premium is in its highest quartile. The model that is estimated is

$$
\mathrm{QQV}_{\mathrm{t}}=\beta_{0}+\beta_{1} * \mathrm{QQV}_{\mathrm{t}-1}+\beta_{2} * \mathrm{RET}_{\mathrm{t}}^{+}+\beta_{3} * \mathrm{RET}_{\mathrm{t}}^{-}+\mathrm{u}_{\mathrm{t}}
$$

\footnotetext{
${ }^{22}$ We originally estimated generalized autoregressive conditional heteroskedasticity (GARCH) models to obtain out-of-sample measures of expected volatility. Convergence was difficult to achieve for out-of-sample forecasts for the first few years of the sample period, however, which is why we estimate the conditional volatility premium as described.
} 
where the QQV on monthly expiration dates is regressed on a constant, its level on the previous expiration date, and separate variables for positive and negative dividend-adjusted QQQ returns over the previous one-month expiration period. Separate values for positive and negative QQQ returns allow for the well-known tendency of implied volatility to react differently to positive and negative equity returns. The estimation results from January 2000 through January 2012 are shown below, with standard errors in parentheses.

$\mathrm{QQV}_{\mathrm{t}}=0.0375+0.7630 * \mathrm{QQV}_{\mathrm{t}-1}-0.1250 * \mathrm{RET}_{\mathrm{t}}^{+}-0.9468 * \mathrm{RET}_{\mathrm{t}}^{-}+\mathrm{u}_{\mathrm{t}}$

$$
(0.0708)(0.0266) \quad(0.0935)
$$

$$
\operatorname{RBAR}^{2}=0.925, \mathrm{DW}=2.36, \mathrm{Q}(12)=13.1(\mathrm{SIG}=0.35), \mathrm{NOBS}=131 .
$$

The estimation results for the entire sample period indicate that the QQV is significantly mean reverting and does not react significantly to greater positive QQQ returns but rises sharply in response to greater negative QQQ returns. The coefficient estimates indicate that $1 \%$ negative QQQ returns are associated with a 0.95 percentage point increase in the QQV and that the halflife of QQV shocks is equal to roughly two and a half months.

We use the following procedure to obtain out-of-sample measures of the volatility premium. We estimate Equation (3) from January 2000 through December 2001 and use the coefficient estimates to obtain QQV fitted values for 2002. We then re-estimate the model with 2002 added to the estimation period and use these estimates to obtain QQV fitted values for 2003. We repeat this procedure to obtain out-of-sample fitted values of the QQV for the period 
January 2002 through January 2012. These fitted values are subtracted from actual QQV values to obtain estimates of the conditional volatility premium.

\section{Covered Call Strategies When the Estimated QQQ Volatility Premium Is High}

This section examines the results of covered call strategies when the conditional volatility premium is in its highest quartile, where the cutoff is a 0.9 percentage point conditional volatility premium. For the 30 months meeting this criterion, the mean volatility premium is 3.43 percentage points and the mean QQV is 29.92 , compared with 24.63 for the entire sample period. ${ }^{23}$ Exhibit 6 shows that when the expected volatility premium is in its highest quartile, the mean monthly return of covered call strategies ranges from $1.11 \%$ to $1.26 \%$, or about double the mean returns for the whole sample period. These higher mean returns are only partially offset by greater semi-standard deviations, which tend to be roughly one percentage point higher than for the entire sample. Sortino ratios range from 0.19 to 0.26 , which compares favorably with a 0.15 Sortino ratio for QQQ returns over the same 30 observations and with a range of Sortino ratios from 0.15 to 0.19 for covered call strategies over the entire sample period. ${ }^{24}$

Entering covered call positions when the ex ante volatility premium is in its highest quartile also results in a greater frequency of gains across all of the covered call strategies. For example, the frequency of gains is $77 \%$ for $2 \%$ OTM covered calls, compared with $71 \%$ for the entire sample period. When the ex ante volatility premium is in its highest quartile, however, the subsequent risk of covered call strategies is greater, as reflected by the semi-standard and

\footnotetext{
${ }^{23}$ These observations are fairly well spread out over the sample period, and only about one-third occur in 2008 and 2009. Unreported results also indicate that entering covered call or short call positions triggered by the QQV being in its highest quartile does not improve risk adjusted returns.

${ }^{24}$ Likewise, standard deviations range from $5.12 \%$ to $6.58 \%$, compared with $3.86 \%$ to $5.55 \%$ for the entire sample. Sharpe ratios range from 0.18 to 0.22 , compared with 0.14 to 0.16 for the entire sample.
} 
standard deviation of covered call returns and a considerably higher average size of losses. For the $2 \%$ OTM covered calls, the average size of losses goes from -5.46 percent for the entire sample to $-6.96 \%$. Overall, the results provide evidence that entering covered call positions only when the volatility premium is in its highest quartile enhances risk-adjusted returns. It is also interesting to note that under these conditions, mean QQQ returns are $0.90 \%$, which is higher than the mean $0.61 \%$ return for the entire sample period. ${ }^{25}$

\section{Delta-Neutral Short Call Strategies When the Volatility Premium Is High}

Exhibit 7 shows the results of entering delta-neutral short call positions when the estimated QQQ volatility premium is in its highest quartile without delta rebalancing. The results indicate better risk-adjusted returns when estimated volatility premiums are high, as the reported Sortino ratios from 0.35 to 0.45 are greater than those for the entire sample period, which range from 0.24 to $0.30 .{ }^{26}$ The mean monthly returns range from $1.26 \%$ for $2 \%$ ITM calls to $2.04 \%$ for 4\% OTM calls. The semi-standard deviations also increase from 3.64\% for $2 \%$ ITM calls to $4.49 \%$ for $4 \%$ OTM calls. On balance, the higher mean returns outweigh higher downside risk measures at higher strike prices, and the Sortino ratios increase from 0.35 for $2 \%$ ITM calls to 0.45 for $4 \%$ OTM calls.

\footnotetext{
${ }^{25}$ Consistent with this evidence, Renicker and Mallick [2005] find that selling fewer calls when implied volatility is high enhances risk-adjusted returns of S\&P 500 index covered call strategies because subsequent equity returns are greater under these circumstances. However, these authors focus on the impact of high levels of implied volatility on covered call strategies, whereas the present study examines the impact of high levels of implied volatility relative to fitted values of implied volatility. Unreported results indicate that the risk-adjusted returns on both QQQ covered call strategies and long QQQ positions are not greater when implied volatility per se is high.

${ }^{26}$ Likewise, the Sharpe ratios of delta-neutral short call positions without rebalancing range from 0.24 to 0.30 when the ex ante volatility premium is in its highest quartile, compared with 0.17 to 0.21 for the entire sample.
} 
We next examine the effect of delta rebalancing on delta-neutral short call positions entered when estimated QQQ conditional volatility premiums are in their highest quartile. Once more, delta rebalancing occurs within a fairly wide band, with deltas flattened by buying or selling QQQ shares when overall deltas fall below -25 or rise above 25 , respectively. The results in Exhibit 8 indicate that mean monthly returns range from $0.86 \%$ for $2 \%$ ITM calls to $1.81 \%$ for $4 \%$ OTM calls, which is below the $1.26 \%$ to $2.04 \%$ range without delta rebalancing. Delta rebalancing again substantially lowers downside volatility, however, and results in considerably higher Sortino ratios, which range from 0.51 to 0.63 , or about $30 \%$ higher than without delta rebalancing. ${ }^{27}$ Delta hedging also results in a greater percentage of profitable outcomes. For example, the percentage of gains for $2 \%$ OTM calls with delta rebalancing is $80 \%$, versus $70 \%$ without delta rebalancing. In addition, the cutoff for the bottom decile of mean returns ranges from $-1.30 \%$ for $2 \%$ ITM calls to $-4.99 \%$ for $4 \%$ OTM calls, compared with $-3.51 \%$ and $6.06 \%$, respectively, without delta rebalancing. These results indicate that selling calls on a deltaneutral basis only when the estimated volatility premium is in its highest quartile substantially improves risk-adjusted returns, which are improved further by rebalancing deltas.

\section{SUMMARY AND CONCLUSIONS}

This study demonstrates that one-month QQQ covered call strategies offer attractive downside risk-adjusted returns relative to long QQQ positions during the sample period from January 2002 through January 2012. This study also provides a framework for analyzing covered call strategies, which decomposes these strategies into initially delta-neutral short call positions

\footnotetext{
${ }^{27}$ Rebalancing deltas similarly improves Sharpe ratios from 0.24 to 0.30 without rebalancing to 0.33 to 0.41 with rebalancing.
} 
and long positions in the underlying instrument. This framework places covered call strategies within a broader class of short option strategies and highlights the separate nature of decisions concerning delta-neutral short call option and long equity exposure. The study then examines the returns from entering delta-neutral short call positions both without and with delta rebalancing and shows that risk-adjusted returns are compelling and improved by rebalancing deltas when they breach fairly wide bands.

The study then assesses whether downside risk-adjusted returns of both covered call and initially delta-neutral short call strategies are enhanced when they are entered only when the estimated volatility premium is in its highest quartile. We use the QQV as a measure of implied volatility and construct out-of-sample fitted values of the QQV from estimated models to gauge the extent to which the expected volatility premiums are high. The results indicate that riskadjusted returns are enhanced when both covered call and delta-neutral short call positions are entered only when estimated out-of-sample volatility premiums are in their highest quartile. Thus, the evidence indicates that entering these strategies when implied volatility is high in light of the market environment improves downside risk-adjusted returns. An implication of these findings is that larger delta-neutral short QQQ call positions may make sense when estimated volatility premiums are greater than usual. In any case, the results are consistent with the view that one-month QQQ call options were meaningfully overpriced over the last decade, which led to attractive risk-adjusted returns on both QQQ covered call strategies and delta-neutral short QQQ call strategies. 


\section{REFERENCES}

Callan Associates. "An Historical Evaluation of the CBOE S\&P 500 BuyWrite Index." Research report, October 2006.

Ederington, L., and W. Guan. "Why Are Those Options Smiling?" The Journal of Derivatives, Vol. 10, No. 2 (2002), pp. 9-34.

Feldman, B., and D. Roy. "Passive Options-Based Investment Strategies: The Case of the CBOE S\&P 500 BuyWrite Index.” The Journal of Investing, Vol. 14, No. 2 (2005), pp. 66-83.

Figelman, I. "Expected Returns and Risk of Covered Call Strategies." The Journal of Portfolio Management, Vol. 34, No. 4 (2008), pp. 81-97.

Hill, J., V. Balasubramanian, K. Gregory, and I. Tierens. "Finding Alpha via Covered Call Writing." Financial Analysts Journal, Vol. 62, No. 5 (2006), pp. 29-46.

Renicker, R., and D. Mallick. "Enhanced Call Overwriting." Lehman Brothers Global Equity Research, November 17, 2005.

Schneeweis, T., and R. Spurgin. "The Benefits of Index Option-Based Strategies for Institutional Portfolios." The Journal of Alternative Investments, Vol. 3, No. 4 (2001), pp. 44-52.

Simon, D. “An Examination of QQQ Option Trades.” Journal of Futures Markets, Vol. 27, No. 8 (2007), pp. 739-770.

Szado E., and N. Kapadia. "The Risk and Return of the Buy Write Strategy on the Russell 2000 Index." The Journal of Alternative Investments, Vol. 8, No. 1 (2007), pp. 30-56.

Szado, E., and H. Kazemi. "Collaring the Cube: Protection Options for a QQQ ETF Portfolio." The Journal of Alternative Investments, Vol. 11, No. 4 (2009), pp. 24-42.

Szado, E., and T. Schneeweis. "An Update of 'Loosening Your Collar: Alternative Implementations of QQQ Collars': Credit Crisis and Out-of-Sample Performance.” Working paper, January 2011. Available online at http://ssrn.com/abstract=1507991. 
Whaley, R., "Return and Risk of the CBOE Buy Write Monthly Index." The Journal of Derivatives, Vol. 10, No. 2 (2002), pp. 35-42. 
Exhibit 1. Preliminary Data on One-Month Call Options and the QQQ Volatility Index (QQV) on Expiration Dates, January 2002-January 2012 (121 observations)

\begin{tabular}{|l|c|c|c|c|c|}
\hline & $2 \%$ ITM & ATM & $2 \%$ OTM & $4 \%$ OTM & QQV Index \\
\hline Midpoint Price & 1.633 & 1.159 & 0.758 & 0.456 & - \\
\hline $\begin{array}{l}\text { Midpoint } \\
\text { Price/QQQ } \\
\text { Price }\end{array}$ & 0.040 & 0.029 & 0.019 & 0.011 & - \\
\hline $\begin{array}{l}\text { Bid-Ask } \\
\text { Spread }\end{array}$ & 0.042 & 0.038 & 0.037 & 0.037 & - \\
\hline $\begin{array}{l}\text { Percent Bid- } \\
\text { Ask Spread }\end{array}$ & 0.026 & 0.033 & 0.049 & 0.081 & - \\
\hline $\begin{array}{l}\text { Implied } \\
\text { Volatility }\end{array}$ & 26.08 & 25.03 & 24.03 & 23.20 & 24.63 \\
\hline $\begin{array}{l}\text { Subsequent } \\
\text { Realized } \\
\text { Volatility }\end{array}$ & 22.65 & 22.65 & 22.65 & 22.65 & 22.65 \\
\hline $\begin{array}{l}\text { Implied Minus } \\
\text { Realized } \\
\text { Volatility }\end{array}$ & 3.43 & 2.38 & 1.38 & 0.55 & 3.43 \\
\hline $\begin{array}{l}\text { Delta } \\
\text { QQQ Price }\end{array}$ & 40.49 & 40.49 & 40.49 & 40.49 & -27 \\
\hline
\end{tabular}


Exhibit 2. Monthly Performance of One-Month QQQ Covered Call Strategies with Varying Moneyness, January 2002-January 2012 (121 observations)

\begin{tabular}{|l|c|c|c|c|c|}
\hline & QQQ & $2 \%$ ITM & ATM & $2 \%$ OTM & $4 \%$ OTM \\
\hline Monthly Return (\%) & 0.61 & 0.61 & 0.69 & 0.70 & 0.77 \\
\hline Semi-Std Deviation & 4.85 & 3.24 & 3.64 & 3.99 & 4.26 \\
\hline Standard Deviation & 6.65 & 3.86 & 4.45 & 4.95 & 5.55 \\
\hline Sortino Ratio & 0.126 & 0.188 & 0.190 & 0.175 & 0.181 \\
\hline Sharpe Ratio & 0.092 & 0.158 & 0.155 & 0.141 & 0.139 \\
\hline Average Gain & 4.87 & 2.11 & 2.64 & 3.21 & 3.81 \\
\hline Average Loss & -5.43 & -4.85 & -5.49 & -5.46 & -5.61 \\
\hline Frequency of Gains & 0.59 & 0.79 & 0.76 & 0.71 & 0.68 \\
\hline Top Decile Returns & 8.41 & 3.50 & 4.01 & 4.45 & 5.73 \\
\hline Bottom Decile Returns & -7.08 & -3.08 & -4.20 & -5.41 & -6.09 \\
\hline
\end{tabular}




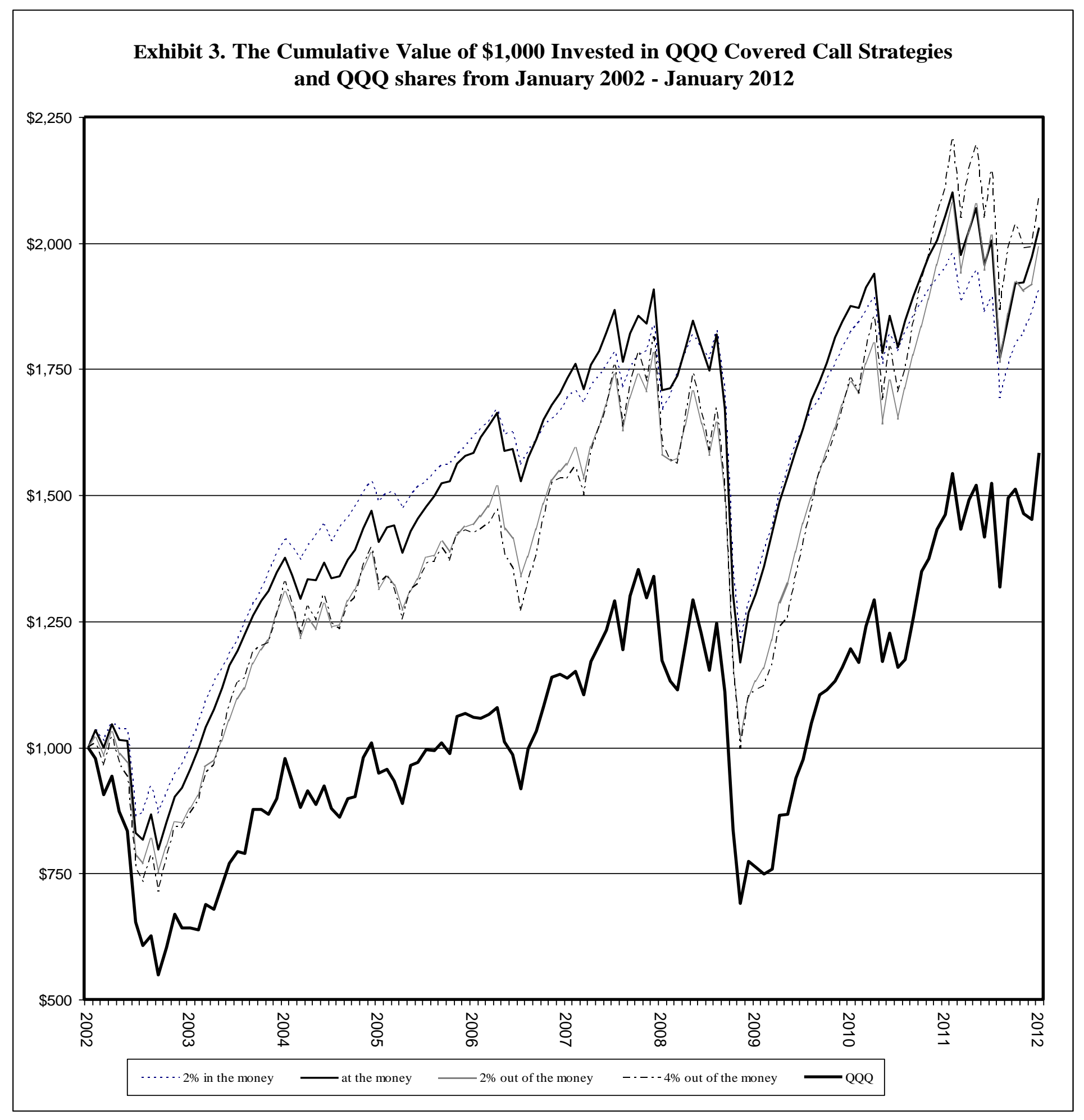


Exhibit 4. Monthly Performance of One-Month Delta-Neutral Short QQQ Call Strategies without Delta Rebalancing, January 2002-January 2012 (121 observations)

\begin{tabular}{|l|c|c|c|c|c|}
\hline & QQQ & $\begin{array}{c}2 \% \text { ITM } \\
\Delta=0.64\end{array}$ & $\begin{array}{c}\text { ATM } \\
\Delta=0.53\end{array}$ & $\begin{array}{c}2 \% \text { OTM } \\
\Delta=0.40\end{array}$ & $\begin{array}{c}4 \% \text { OTM } \\
\Delta=0.27\end{array}$ \\
\hline Monthly Return (\%) & 0.61 & 0.69 & 0.71 & 0.85 & 1.12 \\
\hline Semi-Std Deviation & 4.85 & 2.65 & 3.01 & 3.39 & 3.73 \\
\hline Standard Deviation & 6.65 & 3.84 & 4.30 & 4.79 & 5.47 \\
\hline Sortino Ratio & 0.126 & 0.260 & 0.236 & 0.251 & 0.300 \\
\hline Sharpe Ratio & 0.092 & 0.180 & 0.165 & 0.178 & 0.205 \\
\hline Average Gain & 4.87 & 2.70 & 3.22 & 3.78 & 4.41 \\
\hline Average Loss & -5.49 & -2.57 & -3.11 & -3.92 & -4.63 \\
\hline Frequency of Gains & 0.59 & 0.62 & 0.60 & 0.62 & 0.64 \\
\hline Top Decile Returns & 8.41 & 5.23 & 5.57 & 5.83 & 7.28 \\
\hline Bottom Decile Returns & -7.08 & -2.67 & -3.83 & -4.69 & -5.97 \\
\hline
\end{tabular}


Exhibit 5. Monthly Performance of One-Month Delta-Neutral Short QQQ Call Strategies with Delta Rebalancing, January 2002-January 2012 (121 observations)

\begin{tabular}{|l|c|c|c|c|c|}
\hline & QQQ & $\begin{array}{c}2 \% \text { ITM } \\
\Delta=0.64\end{array}$ & $\begin{array}{c}\text { ATM } \\
\Delta=0.53\end{array}$ & $\begin{array}{c}2 \% \text { OTM } \\
\Delta=0.40\end{array}$ & $\begin{array}{c}4 \% \text { OTM } \\
\Delta=0.27\end{array}$ \\
\hline Monthly Return (\%) & 0.61 & 0.62 & 0.59 & 0.85 & 1.19 \\
\hline Semi-Std Deviation & 4.85 & 1.05 & 1.32 & 1.49 & 2.54 \\
\hline Standard Deviation & 6.65 & 1.93 & 2.16 & 2.47 & 3.97 \\
\hline Sortino Ratio & 0.126 & 0.590 & 0.447 & 0.570 & 0.469 \\
\hline Sharpe Ratio & 0.092 & 0.321 & 0.273 & 0.344 & 0.300 \\
\hline Average Gain & 4.87 & 1.57 & 1.75 & 2.15 & 3.40 \\
\hline Average Loss & -5.44 & -0.98 & -1.44 & -1.77 & -3.12 \\
\hline Frequency of Gains & 0.59 & 0.63 & 0.64 & 0.67 & 0.66 \\
\hline Top Decile Returns & 8.41 & 2.91 & 3.25 & 3.69 & 5.72 \\
\hline Bottom Decile Returns & -7.08 & -1.09 & -1.73 & -1.90 & -4.32 \\
\hline
\end{tabular}


Exhibit 6. Monthly Performance of One-Month QQQ Covered Call Strategies When the QQQ Volatility Index (QQV) Is in Its Highest Quartile Relative to Out-of-Sample Estimates, January 2002-January 2012 (30 observations)

\begin{tabular}{|l|c|c|c|c|c|}
\hline & QQQ & $2 \%$ ITM & ATM & $2 \%$ OTM & $4 \%$ OTM \\
\hline Monthly Return (\%) & 0.90 & 1.11 & 1.20 & 1.26 & 1.20 \\
\hline Semi-Std Deviation & 5.92 & 4.33 & 4.59 & 4.94 & 5.25 \\
\hline Standard Deviation & 7.93 & 5.12 & 5.49 & 6.05 & 6.58 \\
\hline Sortino Ratio & 0.152 & 0.256 & 0.261 & 0.255 & 0.229 \\
\hline Sharpe Ratio & 0.113 & 0.217 & 0.219 & 0.208 & 0.182 \\
\hline Average Gain & 5.43 & 2.69 & 3.09 & 3.77 & 4.00 \\
\hline Average Loss & -5.88 & -9.13 & -8.24 & -6.96 & -8.01 \\
\hline Frequency of Gains & 0.60 & 0.87 & 0.83 & 0.77 & 0.77 \\
\hline Top Decile Returns & 8.64 & 4.28 & 4.40 & 5.72 & 5.25 \\
\hline Bottom Decile Returns & -6.72 & -2.70 & -4.10 & -5.10 & -5.82 \\
\hline
\end{tabular}


Exhibit 7. Monthly Performance of One-Month Delta-Neutral Short QQQ Call Strategies without Delta Rebalancing When the QQQ Volatility Index (QQV) Is in Its Highest Quartile Relative to Out-of-Sample Estimates, January 2002-January 2012 (30 observations)

\begin{tabular}{|l|c|c|c|c|c|}
\hline & QQQ & $\begin{array}{c}2 \% \text { ITM } \\
\Delta=0.64\end{array}$ & $\begin{array}{c}\text { ATM } \\
\Delta=0.53\end{array}$ & $\begin{array}{c}2 \% \text { OTM } \\
\Delta=0.40\end{array}$ & $\begin{array}{c}4 \% \text { OTM } \\
\Delta=0.27\end{array}$ \\
\hline Monthly Return (\%) & 0.90 & 1.26 & 1.38 & 1.70 & 2.04 \\
\hline Semi-Std Deviation & 5.92 & 3.64 & 3.89 & 4.23 & 4.49 \\
\hline Standard Deviation & 7.93 & 5.23 & 5.59 & 6.00 & 6.73 \\
\hline Sortino Ratio & 0.152 & 0.346 & 0.355 & 0.402 & 0.454 \\
\hline Sharpe Ratio & 0.113 & 0.241 & 0.247 & 0.283 & 0.303 \\
\hline Average Gain & 5.43 & 3.72 & 4.08 & 4.65 & 5.32 \\
\hline Average Loss & -5.88 & -3.66 & -4.03 & -5.18 & -5.60 \\
\hline Frequency of Gains & 0.60 & 0.67 & 0.67 & 0.70 & 0.70 \\
\hline Top Decile Returns & 8.64 & 7.89 & 8.52 & 7.62 & 8.70 \\
\hline Bottom Decile Returns & -6.72 & -3.51 & -3.97 & -5.20 & -6.06 \\
\hline
\end{tabular}


Exhibit 8. Monthly Performance of One-Month Delta-Neutral Short QQQ Call Strategies with Delta Rebalancing When the QQQ Volatility Index (QQV) Is in Its Highest Quartile Relative to Out-of-Sample Estimates, January 2002-January 2012 (30 observations)

\begin{tabular}{|l|c|c|c|c|c|}
\hline & QQQ & $\begin{array}{c}2 \% \text { ITM } \\
\Delta=0.64\end{array}$ & $\begin{array}{c}\text { ATM } \\
\Delta=0.53\end{array}$ & $\begin{array}{c}2 \% \text { OTM } \\
\Delta=0.40\end{array}$ & $\begin{array}{c}4 \% \text { OTM } \\
\Delta=0.27\end{array}$ \\
\hline Monthly Return (\%) & 0.90 & 0.86 & 1.12 & 1.10 & 1.81 \\
\hline Semi-Std Deviation & 5.92 & 1.65 & 1.80 & 2.14 & 2.86 \\
\hline Standard Deviation & 7.93 & 2.59 & 2.84 & 3.04 & 4.46 \\
\hline Sortino Ratio & 0.152 & 0.521 & 0.622 & 0.514 & 0.633 \\
\hline Sharpe Ratio & 0.113 & 0.332 & 0.394 & 0.362 & 0.406 \\
\hline Average Gain & 5.43 & 1.86 & 2.24 & 2.25 & 3.53 \\
\hline Average Loss & -5.88 & -1.86 & -2.60 & -3.50 & -5.07 \\
\hline Frequency of Gains & 0.60 & 0.73 & 0.77 & 0.80 & 0.80 \\
\hline Top Decile Returns & 8.64 & 4.10 & 4.09 & 3.68 & 6.31 \\
\hline Bottom Decile Returns & -6.72 & -1.30 & -1.61 & -3.29 & -4.99 \\
\hline
\end{tabular}

